\section{Discovering Opportunities in Times of Change: The Revision to Head Start's Performance Standards and its Implications to Future Childhood Development Research}

\section{Abstract}

With a mission to inform and enlighten readers about impairments and disorders impacting the physical, cognitive, social, and emotional development in children, the Journal of Childhood and Developmental Disorders aims to be a valuable resource on identifying innovative research on the prevention and intervention of developmental disorders. A popular field for the study of childhood development is in the area of early childhood education. Head Start is the largest early childhood education program in the U.S. and recent legislation tasked the Office of Head Start to revise its Performance Standards, which encompasses the rules and regulations for the federally funded program. This editorial identifies and reviews the changes in the Performance Standards proposed by the Office of Head Start in four key areas: Enrollment and attendance, teaching and learning, assessment, and disability standards. The potential outcome of the Performance Standards revision will warrant comprehensive research initiatives that could advance the field of prevention and intervention in early childhood development. Innovative multidisciplinary research in this area is discussed as a befitting contribution to the launch of the Journal of Childhood and Developmental Disorders.

Keywords: Head Start program, education, psychology, children with disabilities, developmental disabilities, early childhood, early intervention (education), special education, growth and development
Krystal T. Cook

Department of Educational Psychology, Texas A\&M University, TX, USA

Corresponding author: Dr. Krystal T. Cook

Department of Educational Psychology, 704 Harrington Tower, MS 4225, Texas A\&M University, College Station, TX 77843, USA.

\section{ktcook@cehd.tamu.edu}

Tel: (979) 845-3447

Fax: (979) 862-1256

\section{Citation: Cook KT. Discovering} Opportunities in Times of Change: The Revision to Head Start's Performance Standards and its Implications to Future Childhood Development Research. J Child Dev Disord. 2015, 1:1.

Received: October 14, 2015; Accepted: October 17, 2015; Published: October 24, 2015

\section{Editorial}

Discovering Opportunities in Times of Change: The Revision to Head Start's Performance Standards and its Implications to Future Childhood Development Research

It is such an exciting opportunity to be part of the inaugural issue of the Journal of Childhood and Developmental Disorders (JCDD). The mission of JCDD is to inform and enlighten readers about impairments and disorders impacting the physical, cognitive, social, and emotional development in children. Moreover, this journal aims to be a valuable resource on identifying innovative contributions to the study of childhood developmental disorders. Congruent to the journal's goals, this editorial aims to highlight a critical arena of the childhood development literature; advancing research initiatives in early childhood education programming. Specifically, recent events among the U.S. federal government should give researchers a renewed interest in evaluating the effectiveness of Head Start programming and its long-term impact on children at-risk for developmental concerns.

\section{Early Childhood Education Programs and Head Start}

Enrollment into early childhood education programs has grown over the last 25 years, with $65 \%$ of 3 - to 4 -year-olds and $84 \%$ of 5-year-olds enrolled in some kind of pre-primary education program [1]. Studies continue to demonstrate that early childhood education programs in general have statistically significant short- 
term and long-term effects, especially in the areas of cognitive development [2]. Furthermore, the benefits of high-quality early childhood education programs for minority children and those from low-income families are well-supported and necessary, especially when research shows at-risk children may start school up to fourteen months behind their peers [3].

Educational difficulties among minority children and students from low-income families have been a popular area of focus; a primary research objective in education emphasizes the closing of this "achievement gap." Educational attainment differences based on race and income has implications beyond the achievement gap. One could assume a "disability gap" exists in the identification and treatment of children. Those who live in poverty have a disadvantage upon school entry across academic areas, in addition to limited access to high-quality schools and health care. According to McLoyd [4], living in poverty has "detrimental" (p. 185) effects on a child's cognitive skills due to increased likelihood of perinatal complications, greater risk for developmental disabilities and illnesses, difficulties with selfregulation, and decreased levels of academic achievement. With the number of U.S. children under the age of 6 living in lowincome or impoverished homes currently at $48 \%$ and growing [5], it is important for research scientists to address the negative impact this reality has on children's overall development.

In 1964, President Lyndon B. Johnson proposed legislation to reduce the national poverty rate in the U.S. by declaring a "War on Poverty." The legislation allocated federal funding towards program to address the poverty crisis at the time. One such program stemming from his initiative was Head Start. Head Start is the largest early childhood education program in the U.S. and it focuses on early intervention to promote healthy child development and school readiness for children birth to age 5. The Office of Head Start identified program goals centering around five domains: physical development and health, social and emotional development, approaches to learning, language and literacy, and cognition and general knowledge [6].

Head Start programming has demonstrated effectiveness for children of low-income families in the areas of cognitive, behavioral, and physical development. Head Start participants have shown consistent gains in cognitive abilities such as language and literacy $[7,8]$, with evidence from a national longitudinal study of closing the gap between low-income children and their more fortunate peers [9]. The early childhood education program promotes increased social engagement among parents, improving efficacious literacy practices in the home environment and more appropriate discipline methods $[10,11]$, which are important variables promoting healthy cognitive and behavioral development. Attendance in Head Start programming has shown decreases in early aggressive and externalizing behaviors, which has implications for decreasing behavior and achievement problems later in school [10]. There is also evidence of increased social emotional readiness among Head Start students. Love et al. [10] found increased sustained attention and parent engagement among children in Head Start, yielding better selfregulation and lower impulsivity in later years. Furthermore, Head Start participation improves motor skills, hygiene practices, health outcomes, and the likelihood to be insured [8], in addition to access to health care, especially among African American children [9]. Ninety seven percent of Head Start families had health insurance and medical homes in the 2014 Head Start Fiscal Year [12]. Overall, there are studies to support that Head Start provides access to quality care for at-risk children in the early development ages, improving their school readiness skills and establishing gains that may last several years after Head Start participation $[11,13]$.

However, such positive findings are not consistent within the literature and some researchers argue that Head Start is ineffective [14], particularly in the long-term [8, 9]. These disheartening conclusions has led to federal reform initiatives by the current administration. Congress, through the Improving Head Start for School Readiness Act of 2007 [15], tasked the Office of Head Start to make significant revisions to their current regulations. These federal requirements for change signals an incredible opportunity for research scientists to participate in the evaluation of Head Start programming to further understand its impact on the cognitive, behavioral, and physical development of the at-risk children and families served.

\section{Proposed Head Start Performance Standards Revi- sions}

Head Start grantees implement early childhood education programming per the Head Start Program Performance Standards. Due to inconsistent research regarding the longterm impact of Head Start's participants, the U.S. Department of Health and Human Services (HHS) released its proposed reforms to the Performance Standards ${ }^{1}$ on June 16, 2015 [16,17]. These changes are 40 years in the making, as it is the first comprehensive revision of the Performance Standards since its inception in 1975. There are approximately 1,400 performance standards the proposal seeks to clarify, streamline, and reorganize to focus on programmatic outcomes while minimizing compliance-driven policies [16]. As the proposed changes were developed based on a comprehensive review of research informing best practices, it is argued that future research initiatives evaluating the efficacy of Head Start's new programming standards will be a necessity for the field of childhood development. Among the various proposed changes submitted, the author identified four areas of significant changes to discuss in this editorial: Enrollment and attendance, teaching and learning, assessment, and disability standards. The following is a discussion regarding the proposed changes in these four areas across the Head Start Performance Standards [17] and its implications for future research.

\section{Enrollment and Attendance Standards}

The most pivotal recommended change is extending the minimum days of operation from 3.5 hours per day and 128 days per year to no less than 6 hours per day and 230 days per year. HHS's comprehensive research on provision of high quality learning and teaching found that Head Start Programs necessitated longer instruction time. This proposed change

${ }^{1}$ To view the proposed Head Start Performance Standards, please reference the U.S. Federal Register: 80 FR 35429 - Head Start Performance Standards [17]. 
will certainly raise the standards and could have a significant impact on mitigating learning losses from extended breaks, especially during the summer and half-day instruction. HHS's revisions of the Performance Standards also proposed to increase opportunities for programs to serve students from economically diverse backgrounds, including making the enrollment of children experiencing homelessness, in foster care, or with disabilities a priority. The recommended provision was based on research demonstrating positive outcomes among children enrolled in economically diverse education programs.

HHS demonstrated an initiative for the consistent enrollment of children in Head Start Programs to reflect the research establishing the impact of consistent and extensive early education on later achievement. Head Start programs are proposed to engage in several intervention strategies including phone calls, home visits, and support services to the families of children who are more than one hour late, absent for four or more days, or absent frequently. Additionally, HHS called for a considerable limitation on the use of suspension and the prohibition of expelling children with behavioral problems. Data was cited revealing an increased rate of expulsions and suspensions in preschool settings (especially among male students of color) and the potential negative impact these practices have on children's educational and life outcomes. HHS advocated consultation with mental health professionals as a primary resource for prevention in this policy area. Overall, increasing enrollment, attendance, and quality of care in early childhood education programs like Head Start can reduce the school readiness gap [18] among other developmental indicators. Comprehensive outcome assessment of these proposed enrollment changes could be one of the most powerful informers to early childhood development intervention.

\section{Teaching and Learning Standards}

The 2015 Head Start Early Learning Outcomes Framework [19] provides the context for program and curriculum alignment standards in the proposed Performance Standards revision. The 2015 version of the Framework was expanded down to birth from the three to five age-group framework issued in 2010. The Framework was developed to be an empiricallybased guide to development across five domains: language and literacy, mathematics, social and emotional development, and physical development [19]. HHS now proposes a requirement of programs to integrate the Framework into all aspects of learning that includes curriculums, lesson plans, and scheduling with an emphasis on language-rich environments and nurturing teacherchild interactions.

The most significant impact of participation in Head Start is on the child's language and cognitive development [2, 3, 7-11]. To expand long-term impacts to include behavioral, social, and physical development, Camilli et al. [2] recommended the following: Make considerations for the type of services provided while ensuring that quality instruction and valuable preschool programming features include small and individualized instruction that is teacher-directed with developmentally appropriate curriculums. The authors further identified a need for more qualitative and quantitative research to identify the mediators to successful development in all domain areas, as well as program evaluation to determine the efficacy of implementation at multiple levels and components. The new Head Start Early Learning Outcomes Framework that is proposed to inform education at all levels across all age groups would be an appropriate target of program evaluation.

\section{Assessment Standards}

The proposed Performance Standards emphasized assessment spanning from administering community needs assessments to individual assessment. HHS would like formal assessment at the program level expanded to every five years from three, and annual formative assessment regarding any community changes. The proposed changes for community assessment focused on requiring Head Start grantees to design services that fit the needs of their community and ensuring priority services to the most vulnerable populations in their respective community (e.g. identifying homeless rates and availability of publicly-funded fullday pre-kindergarten programs). Interestingly, it was proposed to remove requirements outlining the process by which programs must perform these community assessments. It would befit researchers to determine the adequacy of these community assessments across Head Start grantees.

At the classroom level, the Head Start Early Learning Outcomes Framework (Birth-5) will be integrated into assessment. Teachers will be responsible for utilizing child assessment data to inform individual and group lesson planning, such as modifying lessons if developmental delays are identified. Additional changes among assessment standards are discussed in the Disabilities Standards section of this editorial.

HHS is applauded for its emphasis in utilizing more data-driven curriculum development and intervention. Removal of the processes to implement the assessments could have bilateral effects that remain to be seen. However, HHS's proposed regulations for the oversight and possible revocation of Head Start grantees that do not show improvement in meeting children's developmental needs after ongoing assessment demonstrates an aim to ensure high-quality programming.

\section{Disability Standards}

Head Start proposes to revise the Performance Standards to reflect current statutes under the Individuals with Disabilities Education Act (IDEA) [20], including clear language that Head Start grantees cannot deny the enrollment of a child based on their disability or severe health condition. If a child is suspected of having a disability, the proposed Performance Standards will require programs to provide individualized services while the child is being tested to determine eligibility for special education services under IDEA. Head Start recognized that the evaluation process can be lengthy and early intervention of even a suspected disability is critical. Those children who are identified to be eligible to receive services under IDEA will be entitled to full inclusion into the Head Start Program, along with the requirement that all participant families, including those who have children with disabilities in Head Start, have full access to all programming activities and services provided. Additional 
program standards may include language on how Head Start grantees must work closely with their local education agencies to ensure Individualized Education Programs and Individual Family Service Plans are implemented appropriately.

The submitted proposals expands the provision of services to those children with developmental delays that were not significant enough to qualify for services under IDEA. It was recommended that programs must collaborate with the parents of children with delays, identify the means to access appropriate services to prevent further delays, and may use federal funding to support this service provision. If adopted, these outlined changes to disability regulations in the Performance Standards are a victory for children with developmental disabilities and their families.

\section{Conclusions}

Early childhood education is the cornerstone for preventing, identifying, and treating children with developmental disorders. Aside from the home environment, most children will spend a majority of their lifetime in an academic or school environment with the provision of education, social, and health services. For a great number of children, it will be through their local education agency that one is identified as having a disability of some kind. The U.S. Federal Government mandates through the IDEA under the "Child Find" requirement that states must engage in the following:

All children with disabilities residing in the State, including children with disabilities who are homeless children or are wards of the State, and children with disabilities attending private schools, regardless of the severity of their disability, and who are in need of special education and related services, are identified, located, and evaluated...[21].
Head Start served 989,000 families throughout the 2014 fiscal year and children with disabilities eligible for services under IDEA consisted of 12 percent of the total enrollment[12] . As the largest early childhood education program in the U.S., Head Start leads in the formidable responsibility of the early identification and intervention of children with Developmental disabilities. In order to identify, evaluate, and facilitate the provision of services for children with a disability, Head Start and local education agencies utilize multidisciplinary teams to accomplish this mission.

Integrated care through multidisciplinary teams has been shown to demonstrate better outcomes for children [22]. Asarnow et al. [22] conducted a meta-analysis of studies including adolescents and children as young as one year of age and found that the type of care provided through a collaborative team of health specialists including medical doctors, mental health professionals, and care managers had strong effects on health and behavioral health outcomes, especially when utilizing empirically supported interventions. Further, the authors' study was the first known study to analyze the efficacy of collaborative care of children and adolescents, since there was strong evidence of collaborative care efficacy among adults.

The study findings from Asarnow et al. could foster original research that critically evaluates the impact of treatment through collaborative care and integrated interventions among children. Systematic inquiry regarding early childhood education and collaborative care is especially relevant as it is a federal requirement for schools to identify and evaluate children with disabilities through integrated approaches. With the impending changes to the Head Start Performance Standards, contributors to the Journal of Childhood and Developmental Disorders have a great opportunity to engage in multidisciplinary research spanning the fields of medicine, psychology, education, and beyond to guide practice in mitigating childhood developmental disorders and bolstering successful life outcomes. 


\section{References}

1 U.S. Department of Education, National Center for Education Statistics (2015) Fast facts: Preprimary enrollment.

2 Camilli G, Vargas S, Ryan S, Barnett WS (2010) Meta-analysis of the effects of early education Interventions on cognitive and social development. Teachers College Record 112: 579-620.

3 Hull J (2012) Starting out right: Pre-k and kindergarten: Full report. Center for Public Education.

4 McLoyd VC (1998) Socioeconomic disadvantage and child development. Am Psychol 53: 185-204.

5 Yang J, Ekono M, Skinner C (2015) Basic facts about low-income children: Children under 6 Years, 2013. New York: National Center for Children in Poverty, Mailman School of Public Health, Columbia University.

6 U.S. Department of Health and Human Services, Administration for Children and Families (2015) Head Start services.

7 Hanley GP, Fahmie TA, Heal NA (2014) Evaluation of the preschool life skills program in Head Start classrooms: A systematic replication. J Appl Behav Anal. 47: 443-448.

8 U.S. Department of Health and Human Services, Administration for Children and Families (2010) Head Start impact study. Final report. Washington, DC.

9 Currie J, Thomas D (2015) Does Head Start make a difference? Am Econ Rev 85: 341-364.

10 Love JM, Kisker EE, Ross C, Raikes H, Constantine J, et al. (2005) The effectiveness of Early Head Start for 3-year-old children and their parents: Lessons for policy and programs. Dev Psychol 41: 885-901.

11 Vogel C, Brooks-Gunn J, Martin A, Klute MM (2013) Impact of Early Head Start participation on child outcomes at ages 2, 3, and 5 . Monogr Soc Res Child Dev 78: 36-63.
12 U.S. Department of Health and Human Services, Administration for Children and Families (2014) Head Start Program Facts: Fiscal Year 2014.

13 Hillemeier, MM, Morgan, PL, Farkas, G, Maczuga, S. Quality disparities in child care for at-risk children: Comparing Head Start and non-Head Start settings. Maternal and Child Health Journal. 2013; 17: 180-188. doi: 10.1007/s10995-012-0961-7.

14 Barnett WS (2011) Effectiveness of early educational intervention. Science 19: 975-978.

15 Improving Head Start for School Readiness Act of 2007, Pub. L. 110134,42 USC $\S 9801$ et seq.

16 U.S. Department of Health and Human Services (2015) News: HHS proposes vision for the future of Head Start releases new performance standards.

17 U.S. Department of Health and Human Services, Administration for Children and Families (2015) Head Start Performance Standards: A proposed rule by the Children and Families Administration on 06/19/2015, 80 FR 35429.

18 Magnuson KA, Waldfogel J (2015) Early childhood care and education: effects on ethnic and racial gaps in school readiness. Future Child 15: 169-96.

19 U.S. Department of Health and Human Services, Administration for Children and Families (2015) Head Start Early Learning Outcomes Framework.

20 Individuals with Disabilities Education Act, 20 (2004) U.S.C. Sect. 1400.

21 Child Find, 34 C.F.R. Sect. 300.11(a)(1)(i) (2004).

22 Asarnow J, Rozenman M, Wiblin J, Zeltzer L (2014) Integrated medical-behavioral care compared with usual primary care for child and adolescent behavioral health: A meta-analysis. JAMA Pediatr 169: 929-937 